\title{
INTERNALIZATION OF TEACHER EDUCATION AS A PART OF A UNIVERSITY INTERNALIZATION STRATEGY
}

\author{
Yulia Lopukhova \\ Samara State Technical University, Russian Federation \\ Elena Makeeva \\ Samara State University of Social Sciences and Education, \\ Samara State Technical University, Russian Federation \\ Kseniya Kuzovenkova \\ Samara State Technical University, Russian Federation
}

\begin{abstract}
The internationalization of University teacher education is very important today since teachers have to prepare students for living and working in the new global world. To prepare students for the globalization of the society, university teachers should have the opportunity to gain international experience - from traditional studies and internships to summer schools and degree theses abroad, blended learning formats, buddy programmes, international field trips to preparing English-language degree programmes together with international colleagues. In this paper the authors describe the IDUTE programme (International Dimension of University Teacher Education) designed to enhance the international dimensions of various components of University teacher education programmes, to transform courses in order to facilitate change and improvement in reaching the internationalization goals of their work and to help provide University teachers with greater global competence. This paper details the nature and specifics of the IDUTE programme and provides details of the programme's outcomes and results. The authors have done extensive research to determine both the existing international content and programme practices for University teacher education and perceived needs for improvement. The IDUTE programme promotes internationalisation among technical teachers and students and expands intercultural competence into their studies and career through creation and development of separate 16/36/72-hour modules on international activities of University Teachers.
\end{abstract}

Keywords: internationalization, teacher education, intercultural competence, modules on international activities.

\section{Introduction}

Russian system of education was built for an economy and a society that no longer exists. In the 21st century, students require levels of information and technological literacy that go far beyond the basic knowledge that was sufficient 
in the past. Today's students must be prepared to solve new challenges many of which are of global origin. And to prepare students for living and working in this new world and for the globalization of the society is one of the main tasks for university education and university teachers.

In content, teacher education in Russia has traditionally focused almost exclusively on developing competences appropriate for teaching in local HEIs. While the tremendous influence of globalization and the importance of intercultural communication have been clear for some time, little attention has been given to the question of how to make curriculum more reflective of international dimensions and concomitantly how to prepare more internationally competent teachers. Teacher education is responsible for preparing teachers to be effective in the modern global world. If they are to be effective in teaching students to be more aware of and knowledgeable about the rest of the world as well as more sensitive to global perspectives teachers must themselves possess appropriate knowledge and skills. Thus, teacher education needs to change.

At the same time, the majority of technical and vocational teachers who work in technical universities at the moment were trained at university-level institutions, but their curriculum was practice-oriented and did not include either special education subjects or subjects preparing them to successfully collaborate within international community.

That is why, at Samara State Technical University (SSTU), we have been engaged in a development programme designed for technical and vocational teachers to enhance the international dimensions of various components of our teacher education programmes and to transform courses in order to facilitate change and improvement in reaching the internationalization goals of our work. The IDUTE programme (International Dimension of University Teacher Education) was developed with the support of Samara State Social-Pedagogical University. This cooperation has helped form a core of faculty leaders in the effort to enhance internationalization and to transform a variety of courses and provide our teachers with greater global competences. This paper details the nature and specifics of the programme, and it provides details of the programme's outcomes and results.

We have done extensive research to determine both the existing international content and programme practices for teacher education and the perceived needs for improvement. Among the 14 universities and colleges we studied, we found that teacher education programmes were generally very weak on international dimensions but clearly aware of the specific needs for improvement they needed to explore. One of the reasons for is absence of the clear international strategy of the most Russian Universities. We hope that the IDUTE programme as well as this research will help at least Samara State Technical University develop its own international strategy. 
SOCIETY. INTEGRATION. EDUCATION

Proceedings of the International Scientific Conference. Volume I, May $22^{\text {th }}-23^{\text {th }}, 2020.510-520$

\section{Literature review}

The problem of internationalization of education is not new but still crucial for the education society. Back in 2008 we find the extensive review of model teacher education efforts toward internationalization in the U.S. illuminates the steps they recommend for development in this area (Teacher Preparation ..., 2008). These include:

- Engage Leadership and faculty and develop a plan;

- $\quad$ Create a Globally Oriented General Education Programme;

- Recruit students with International Interests and Experiences into Teaching;

- $\quad$ Faculty Development for Global Teaching and Learning;

- $\quad$ Recruiting and Rewarding Internationally Minded Teacher Educators;

- Globally Focused Faculty Professional Development;

- International Experiences for Faculty;

- Visiting International Faculty;

- Internationalize Professional Education Courses;

- Offer International Experiences at Home, Abroad, and Online.

Literature related to internationalization of education, and specifically of teacher education, is growing. A number of individual educators, as well as organizations, have published articles, monographs, and books emphasizing the need to change programmes and the kinds of changes that would help enhance the global dimensions of those programmes. We have already done a detailed literature review of internationalization of education in our previous article (Lopukhova \& Makeeva, 2018).

Here we would like to highlight the fact that to develop really internationally competent technical and vocational teachers we, as a course designers, have to remember that our learners are adults with rich previous background and experience. They are busy and stressed-out researchers who hate wasting time. They want learning experiences that help them meet their needs and achieve their goals. When creating any type of courses, it is important to base the design on a good understanding of adult learning. The Andragogy theory, developed by Malcolm Knowles in the 1970s, clarified that adult learners differ from children in the following six ways:

1. Need for Knowledge: Adults need to know "why" they should learn.

2. Motivation: Adults are driven by internal motives. They will learn if they want to learn. For instance, a compelling answer to the "what's-init-for-me" question is a powerful internal motivation.

3. Willingness: For adults, the willingness or readiness to learn comes from perceiving the relevance of the knowledge. They want to know 
how learning will help them better their lives, and they learn best when they know that the knowledge has immediate value for them.

4. Foundation or Experience: Adults bring with them rich reserves of experiences that form the foundation of their learning. They analyze, rationalize, synthesize, and develop new ideas or tweak old ones through the filter of their experiences. As an instructional designer, you should tap into their experiences to help them make connections, perceive relevance, and derive inspiration.

5. Self-Direction: Adults are self-directed individuals who want to take charge of the learning journey. They are independent beings who want to feel in control.

6. Orientation to Learning: Adults learn best when they "do.” They find relevance in task-oriented learning, which they can align with their workplace realities. Besides, task-oriented learning exercises their problem-solving ability that in turn, gives them the confidence that they can conquer their challenges with their newly-acquired knowledge.

In addition, David A. Kolb reveals the cyclical nature of experiential learning by explaining how it takes place in four stages (Kolb, 1984, 2001):

1. Concrete Experience (CE): Adults learn best when the learning experience goes beyond the chalk-and-talk routine. Kinesthetic learning or learning by encouraging physical actions (simulations) and learning that evokes strong emotional responses (realistic scenarios that reveal cause-effect relationships) create powerful experiences that are not forgotten easily.

2. Reflective Observation (RO): Adults need to engage with and reflect on their experiences to glean insights and acquire knowledge. So it is critical to not only create opportunities for experience-based learning but also provide time and space to encourage reflection. Create opportunities for "watching" the action unfold before the eyes (demonstrations) and "analyzing” processes and procedures (scenariodriven activities, case studies).

3. Abstract Conceptualization (AC): The success of experiential learning lies in the learner being able to decode abstract concepts from their reflections, generalize these ideas, and realize the relevance to their reality. Designs assessments to encourage learners to exercise their "critical thinking" abilities, so they can formulate concepts and procedures.

4. Active Experimentation (AE): Role-playing activities, internships, and other hands-on tasks let learners apply the learning and thus truly "learn by doing." Active experimentation leads to concrete experiences, and the cycle of experiential learning resumes. 
While developing the IDUTE programme we took into account these adult education peculiarities and involved technical and vocational teachers into active actions to make them use their previous knowledge and experience in a new international dimensions context.

\section{IDUTE programme}

The IDUTE programme (International Dimension of University Teacher Education) was designed in 2017 to enhance the international dimensions of various components of University teacher education programmes, to transform courses in order to facilitate change and improvement in reaching the internationalization goals of their work and to help provide University teachers with greater global competences.

The IDUTE programme modules were designed after deep studying of technical and vocational teachers' needs. It promotes internalization among them and also expands international activities which help form internationally competent teachers. The IDUTE programme includes:

Module 1. Summer Schools (16 hours);

Module 2. CLIL Methodology in a Technical Classroom (72 hours);

Module 3. Making Successful Applications for International Grants (72 hours);

Module 4. International Conferences and Networking: Participating \& Organizing (16 hours);

Module 5. How to Write an Article in an International Journal (36 hours);

Module 6. Buddy Programmes \& International Field Trips (16 hours);

Module 7. Digitalization of Education: Online Courses for Foreign Students (72 hours);

Module 8. Developing Double-Degree Programmes (16 hours).

The programme came into force in the autumn term of 2017 as separate 16/36/72-hour modules which were offered for SSTU technical teachers and is still been developed. The teachers are supposed to choose 2-4 modules a year thus covering the whole programme within the period of 2-3 years.

We further present the content of the first two modules which were tested and endorsed as pilot courses in 2017 and their current results.

\section{Module 1. Summer schools (SS)}

This 16-hour module introduces University Summer Schools as the form of life learning, career and recreation. It introduces the purpose of a summer school as getting new knowledge, skills, competencies on major and other branches of studies, in developing interdisciplinary fields which lets participants be involved in research and practical activity. 
The module shows the role of SS which lies in reaching the internationalization goals as SS activities positively influence on corporate culture, provide the special atmosphere of interaction between academic staff and students. It demonstrates that SS activities encourage the formation of regional and international professional network by interest, provide innovative professional development for educators and offer teachers a chance to test new models of teaching and gain valuable leadership experience.

The module particularly stresses that personal contacts make special academic environment and summer schools create a positive university image and become a kind of university business card, a university brand. They can promote the implementation of the university's social mission, strengthen public relations (Nazarova, 2017).

The course clearly defines parameters that typically set a summer programme apart from just a summer activity. These parameters are as follows (McLaughlin \& Pitcock, 2009):

- $\quad$ SS operates strictly during the summer months;

- $\quad$ SS has a specific starting and ending time for activities;

- $\quad$ SS has an operator responsible for administration, implementation, and finances;

- $\quad$ SS is supported by revenue and employs paid staff (from both the host university and some guest professors);

- $\quad$ SS targets a specific group of youth to participate;

- $\quad$ SS meets a specific university or community need and has one or more youth-centered goals;

- $\quad$ SS offers students enough exposure to the activities to meet the need or make the goal attainable.

Teachers who attended this course analized and defined organizing features for perspective SS:

- $\quad$ SS status (local, all-Russia ot international);

- $\quad$ SS profile (monodisciplinary or interdisciplinary);

- $\quad$ SS programme focus (the primary goals and activities offered through the programme:

- SS duration (the average amount of programming available to the typical participant over one summer; also whether the programme is designed to serve youth one-time (one summer); or over multiple summers;

- $\quad$ SS target audience (just bachelor and master students; post-graduates and young university teachers, perspective applicants / senior school children, etc) and whether participation is mandatory or voluntary; 
- $\quad$ SS connections (whether or not the programme is connected to a larger network that influences its quality).

Course participants also analyzed 10 existing SS programmes from different Russian Technical universities and worked out recommendations that would improve the quality of these summer schools:

- SS participation should be expanded from students struggling academically to all students;

- SS focus should be shifted from narrow remediation and test preparation to a blended approach of both academic learning in core subject areas and hands-on activities that foster critical 21st century competitiveness skills like collaboration, innovation, creativity, communication, and data analysis;

- SS organizers should strengthen and expand partnerships with university international partners, community-based organizations and public agencies, improve programme quality and develop shared outcomes for summer success, etc.

As a result, out of 12 technical teachers who signed up for the module 10 teachers completed the course and presented their SS programmes. In summers 2018, 2019 they organized several summer schools, in SSTU, e.g.:

- SS “BIM Technologies” (Building Information Modeling), organized in association with GRAPHISOFT, one of the largest architectural CAD companies in the world, was held in a truly international environment as it attracted students from both SSTU (including international students) and from its European and Asian partner universities;

- SS "Heritage Materials and Techniques" turned out to be an unforgettable two-week event for students specializing in architecture and civil engineering from several Russian Universities. These students had a chance to work with international teaching staff and were really inspired by the SS.

\section{Module 2. CLIL Methodology in a Technical Classroom}

CLIL Methodology in a Technical Classroom is a 72-hour module which focuses on both content and language. Its dual purpose consists in showing technical teachers that, on the one hand, CLIL (Content and Language Integrated Learning) is the methodology which can be successfully applied to engineering subjects (especially those focused on innovation and entrepreneurship) thus fostering integrated learning of languages. In this respect, it benefits students immensely preparing them for social, professional, and civic environments that are in many ways very different. On the other hand, the module highlights that while adopting this methodology, educators also need to revolutionize 
themselves, modernize their educational technology as content and language integration requires a particular teaching method, acquire sufficient English proficiency, develop and perfect their intercultural competences (Coyle, 2009).

While covering the content of this module, participants get to know CLIL theory and clearly see that in this approach, knowledge (Content) used in a real sociocultural context is practiced in a learning context (Communication) through the implementation of the 4-Cs-framework. Thinking skills (Cognition) and intercultural skills (Culture) need to be developed through teaching and learning interaction thus serve both students and teachers interests. It is particularly stressed that CLIL starts with technical and vocational teachers themselves, this approach implies that content teachers should be linguistically and culturally competent (Dalton-Puffer et al., 2010). These teachers are to encourage learners to develop cultural awareness and participate in social activities through the instructional language and they are themselves engaged in these activities.

Practical materials analyzed by participants in this module are of great relevance as the authors have previously used CLIL in SSTU. For example, Entrepreneurial Leadership course was offered during the Fall 2014 semester for the first time in the frame the Masters' Programme "Entrepreneurs for Tomorrow". The first version of the course included various topics such as Evolution of the Concept of Entrepreneur, Characteristics of an Entrepreneur, Entrepreneurship Development, Innovation and Entrepreneurship, Risks Involved with Entrepreneurship, Barriers to Entrepreneurship, Types of Entrepreneurs, Entrepreneurial Competencies, Entrepreneurial Strategies and others. During the course, a problem-based learning approach was utilized, assigning the students to work with a business plan. The group was broken down into 3-4-student teams. Each team was asked to write business plans. To help student understand the content in English, the researchers planned lessons using one of the bridging pedagogies of CLIL approach as "the Genre Egg” (Lin, 2016). According the Genre Egg, there are three circles which visualize demands of students. In the innermost circle ('field'), the key vocabulary necessary for students to build their knowledge. In the middle circle of the role relationships ('tenor') between teacher and students are mapped out, moving students gradually from the everyday role of 'student' to more discipline-specific roles of an entrepreneur, an owner of his/her own business while the teacher's roles shift among co-explorer, coordinator, demonstrator-expert, consultant and so on. In the outermost circle (mode), the different modes of communication are mapped out, moving students gradually along the mode continuum of field notes, oral and written recounts to more formal academic genres such as an information report.

As a result, most technical teachers who signed up for the module completed it and started integrating CLIL approach into their own courses. Thus, now in 
SSTU the following courses (or their parts) are taught through CLIL methodology: History, Mathematics, Programming Fundamentals, Organizational Psychology, Innovation and Entrepreneurship, etc. which is especially helpful for international students who study at SSTU.

\section{Modules 3-8.}

As for other modules, 72-hour-Module 3 (Making Successful Applications for International Grants was first introduced in the autumn term of 2018. The course was entirely practice-oriented as the teachers analyzed grant applications previously submitted for European grants and formulated their own grant proposals.

Module 4 (International Conferences and Networking: Participating \& Organizing) resulted mainly in the fact that an international forum "Future Cities" and "Civil, Architectural and Environmental Sciences and Technologies" (CAEST 2019) international science-research conference were for the first time held in Russia, in SSTU (November 2019).

Modules 5 \& 6 have no evident results at the moment as they were firstly introduced only in the autumn of 2019. Modules $7 \& 8$ are still under construction and will be introduced in further research papers.

\section{Conclusion}

The IDUTE programme modules gave an impetus to the University internationalization strategy at a level of university teachers and staff and increased:

- $\quad$ teaching staff mobility (incoming mobility: participation of foreign teachers in a teaching process),

- $\quad$ teaching staff mobility (outgoing mobility: participation of university teachers in a teaching process at foreign universities),

- participation in video conference meetings, development and fulfillment of distance learning courses,

- participation in international conferences, international research projects, joint studies, preparation of joint publications,

- participation in international educational projects, creation of joint international educational programmes,

- available international content in a scope of subjects,

- $\quad$ lecturing in foreign languages.

This in turn became the basis for systematic work on internationalization of teaching and studies at the student level.

As a result, now we have a pool of teachers and an administrative staff who are ready to develop an internationalization strategy at the University management level on the following fields: 
Lopukhova et al., 2020. Internalization of Teacher Education as a Part of a University Internalization Strategy

1. Partnerships and Networks;

2. Welcome Culture and Support for International Students and Researchers;

3. Research, Knowledge and Technology Transfer;

4. University International Visibility.

\section{References}

Altbach, P.G., \& Teichler, U. (2001). Internationalization and Exchanges in a Globalized University. Journal of Studies in International Education, 5(1), 5-25

Cheng, Y.C. (2000). A CMI-Triplization Paradigm for Reforming Education in the New Millennium. International Journal of Educational Management, 14(4), 156-174

Coyle, D. (2009). Promoting Cultural Diversity through Intercultural Understanding: A Case Study of CLIL Teacher Professional Development at In-service and Pre-service Levels. In M.L. Carrió-Pastor (Ed.), Content and Language Integrated Learning: Cultural Diversity (Vol. 92, pp. 105-124). Frankfurt am Main: Peter Lang.

Coyle, D., Hood, P., \& Marsh, D. (2010). CLIL: Content and Language Integrated Learning. Cambridge: Cambridge University Press.

Guri-Rosenblit, S. (2015). Internationalization of Higher Education: Navigating Between Contrasting Trends. The European Higher Education Area, 13-26.

Dalton-Puffer, C., Nikula, T., \& Smit, U. (Eds.). (2010). Language Use and Language Learning in CLIL Classrooms. John Benjamins Publishing.

Knowles, M. (1984). Andragogy in Action. San Francisco: Jossey-Bass.

Kolb, D.A. (1984). Experiential learning: experience as the source of learning and development (Vol. 82). Englewood Cliffs, NJ: Prentice Hall.

Kolb, D.A., Boyatzis, R.E., \& Mainemelis, C. (2001). Experiential Learning Theory: Previous Research and New Directions. The Educational Psychology Theories, 227-247. Retrieved from https://www.d.umn.edu/ kgilbert/educ5165-731/Readings/experiential-learningtheory.pdf

Lin, A.M.Y. (2016). Language Across the Curriculum \& CLIL in English as an Additional Language (EAL) Contexts: Theory and Practice. Springer.

Lopukhova, Y., \& Makeeva, E. (2018). Teaching entrepreneurship through a CLIL approach in Russian technical universities. Society, integration, education. Proceedings of the International Scientific Conference. Volume I, Higher Education, 328-341. DOI: http://dx.doi.org/10.17770/sie2018vol1.3189

Lopukhova, Y., \& Suchkov, D. (2016). Aspects of preparation and evaluation of international master thesis in the programme "Entrepreneurs for Tomorrow" in the framework of Tempus project. In New strategies of learning activities assessment: International Conference Proceedings (pp. 242-252). Samara, SGASU.

Makeeva, E., \& Spaubeck, J.M. (2016). International master thesis: structure and content requirements in the framework of the programme "Entrepreneurs for Tomorrow" (Tempus IV Project). New strategies of learning activities assessment: International Conference Proceedings, 222-229.

Marsh, D., Mehisto, P., Wolff, D., \& Frigols Martín, M.J. (2010). European Framework for CLIL Teacher Education. European Center of Modern Language.

McIntyre-Bhatty, T. (2019). Continuous Development of Teaching Competences. Thematic Peer Group Report. EUA: Learning and Teaching paper (Brussels, EUA). 
SOCIETY. INTEGRATION. EDUCATION

Proceedings of the International Scientific Conference. Volume I, May $22^{\text {th }}-23^{\text {th }}, 2020.510-520$

McLaughlin, B., \& Pitcock, S. (2009). Building Quality in Summer Learning Programs: Approaches and Recommendations. National Summer Learning Association. Retrieved from https://www.wallacefoundation.org/knowledge-center/Documents/BuildingQuality-in-Summer-Learning-Programs.pdf

Melekhina, E., \& Kazachikhina, I. (2016). Teacher-Retraining Course Design Renewal. SinoUS English Teaching, 13(2), 150-161.

Nazarova, I. (2017). University summer school: the technology of organization and learning. Higher Education in Russia, 8-9, 57-63.

O'Hara, S. (2009). Vital and Overlooked: The Role of Faculty in Internationalizing U.S. Campuses. In Meeting America's Global Education Challenge (pp. 38-45). Issue 6. New York: Institute for International Education.

Teacher Preparation for the Global Age: An Imperative for Change. (2008). Longview Foundation for Education in World Affairs and International Understanding, Inc. Silver Spring, MD 20910. Retrieved from https://longviewfdn.org/index.php/download_file/ force/10/

Wächter, B. (1999). Internationalisation in Higher Education - A Paper and Seven Essays on International Cooperation in the Tertiary Sector. Ed. Bernd Wächter. Bonn: Lemmens Verlags \& Mediengesellschaft. 